\title{
Spatial and temporal dynamics of water in the root environment of potted plants on a flooded bench fertigation system
}

\author{
W. OTTEN ${ }^{1, *}$, P.A.C. RAATS ${ }^{2}$, R. BAAS ${ }^{3}$, H. CHALLA ${ }^{4}$ AND P. KABAT $^{5}$
}

${ }^{1}$ DLO Research Institute for Agrobiology and Soil Fertility (AB-DLO), P.O. Box 129, NL-9750 AC Haren, The Netherlands, and Wageningen Agricultural University, Department of Horticulture, Haagsteeg 3, NL-6708 PM Wageningen, The Netherlands. (Present address: Department of Plant Sciences, University of Cambridge, Downing Street, Cambridge CB2 3EA, United Kingdom)

${ }^{2}$ Wageningen Agricultural University, Department of Agricultural, Environmental and Systems Technology, Division of Mathematics, Dreijenlaan 4, NL-6703 HA Wageningen, The Netherlands

${ }^{3}$ Research Station for Floriculture and Greenhouse Vegetables, Linnaeuslaan 2a, NL-1431 JV Aalsmeer, The Netherlands

${ }^{4}$ Wageningen Agricultural University, Section of Agricultural Engineering and Physics, Bomenweg 4, NL-6703 HD Wageningen, The Netherlands

${ }^{5}$ DLO Winand Staring Centre for Integrated Land, Soil and Water Research (SC-DLO), P.O. Box 125, NL-6700 AC Wageningen, The Netherlands

* Corresponding author (fax: +44 1223 333953; e-mail:wo200@cus.cam.ac.uk)

Received 12 June 1998; accepted 11 November 1998

\begin{abstract}
The relationship between evapotranspiration of potted plants on a flooded bench fertigation system and the realised distribution of water in the root zone was studied in detail for a range of fertigation schedules. The physical characteristics of the peat-based potting medium are described by models commonly used in soil physics. The functioning of the substrate in practical situations was highly affected by hysteresis in the water retention characteristic. Daily evapotranspiration of Ficus benjamina plants varied from 0.4 to $4.1 \mathrm{~kg} \mathrm{~m}^{-2}$ day $^{-1}$, of which $19-41 \%$ was lost by evaporation. Water uptake by plant roots resulted in near hydrostatic equilibrium conditions as long as the volumetric water content was above 0.22. Lower average water contents resulted in locally drier conditions in the root environment. The absorption of water during irrigation depended on the soil physical conditions and increased with decreasing volumetric water content before flooding. The majority of the water absorption occurred within the first minutes, making frequent fertigation more effective than increasing the duration. Actual buffer capacity of the potting medium is defined and by combining measured absorption during flooding with data on evapotranspiration, we indicate how minimum requirements of the fertigation schedule can be derived.
\end{abstract}

Keywords: evapotranspiration, horticultural media, hydraulic conductivity, hysteresis, water retention. 


\section{Introduction}

Composition of horticultural media and fertilization techniques have undergone enormous changes recently. Forced by more stringent environmental regulations, there is an increasing interest in growing systems in which there is no leaching of nutrients into subsoil and in which leaching to surface water is minimized (Van Os et al., 1991). To maintain a less polluting, sustainable and competitive horticultural sector, new growing systems are still under investigation. For potted plants there is a growing interest in ebb-flood fertigation systems (Ploeger, 1992), where plants are irrigated from below. In combination with benches, this system, often referred to as flooded bench fertigation system, allows for reuse of surplus of water and nutrients. Water and nutrients are added to the pot by flooding benches on which the plants are standing. During flooding, plants are standing in a nutrient solution, usually to a height of $0.02 \mathrm{~m}$, and are allowed to take up water and nutrients for a short period, e.g. five minutes. For a given fertigation duration and height, the supply of water to the plant is dictated by hydraulic characteristics and initial wetness of the potting medium. In between fertigations a plant relies on the buffer capacity of the potting medium. There have been many efforts to relate fertigation schedules in combination with physical characteristics to plant growth. On the flooded bench growing system, optimal plant growth is generally obtained for media having a high air content at high matic heads, in combination with high fertigation frequency (De Krey and Straver, 1988). On the other hand, drier conditions are sometimes more favourable if more compact plants are required. Control of the water status in the potting medium is relatively complicated, since the supply of water and nutrients cannot be controlled directly. For a given fertigation duration, this supply is determined by the size of the container, and the physical characteristics and the initial wetness of the potting medium. Optimizing the fertigation schedule requires knowledge of capillary rise, of air/water ratios in the potting medium, and of evapotranspiration and redistribution of water in the medium. Simulation models based on basic soil physical theory for the dynamics of water in the root zone environment can contribute to optimal design of horticultural growing systems and to define suitability of substrates (Otten, 1994; Heinen, 1997). However, development and testing of such models demands a detailed study of the fertigation system and a range of measurements and characterizations which have only been rarely done for horticultural media.

The principal objectives in this paper are to increase our understanding of flooded bench fertigation and to obtain a data set which will allow for validation and parameterisation of a simulation model. Therefore, the following experimental data were obtained: (i) evapotranspiration in a potted plant system relative to the buffer capacity of the potting medium; (ii) capillary rise during flooding of the pots in relation to initial wetness of the substrate; (iii) the spatial distribution of water within the root environment, in particular to investigate if local drier conditions can occur that may lead to stress for plants; (iv) the water retention characteristic including hysteresis and the hydraulic conductivity characteristic of the potting medium. All measurements were done in modern greenhouses to ensure that conditions reflected those common in practice as much as possible. 


\section{Materials and Methods}

\section{Fertigation schedules and plant growth}

Evapotranspiration from potted plants and dynamics in water content of the potting medium were investigated in three successive experiments. The first and second experiment were conducted in a small greenhouse in the spring and winter of 1990 , respectively. The third experiment was conducted in a larger, more modern, greenhouse in the spring of 1992. Average air temperature was maintained at $23{ }^{\circ} \mathrm{C}$ in all experiments. During the third experiment, air humidity was controlled at $70 \%$. Ficus benjamina exotica plants were potted in plastic pots $\left(0.12 \mathrm{~m}\right.$ height, $10^{-3} \mathrm{~m}^{3}$ volume $)$ filled with a 'flooded bench mix' consisting of $25 \%$ perlite and $75 \%$ peat, and a basal fertilizer of $3.0 \mathrm{~kg} \mathrm{~m}^{-3}$ lime and $0.75 \mathrm{~kg} \mathrm{~m}^{-3}$ of $13 \mathrm{~N}-11 \mathrm{P}-23 \mathrm{~K}$. Plants were placed on benches at a density of 25 plants $\mathrm{m}^{-2}$, and fertigated by flooding the benches with a $0.02 \mathrm{~m}$ layer of nutrient solution, each time of watering. In the first experiment, running from April till June 1990, plants were flooded continuously with a fertigation solution having an EC of $2.2 \mathrm{mS} \mathrm{cm}$, using four tables of $3.8 \mathrm{~m}^{2}$ each. In the second experiment the pots were flooded either continuously or twice a week for 30 minutes with an EC of $1.8 \mathrm{mS} \mathrm{cm}$ c $^{-1}$ This experiment ran from October 1990 till April 1991, using four tables for each treatment (eight tables in total). The fertigation schedules in the third experiment were designed to include both dry and wet conditions, and comprised four irrigation treatments and two EC levels (Table 1). For each treatment, three independently regulated tables of $14 \mathrm{~m}^{2}$ each were used. The experiment ran from March till May 1992. The fertigation schedule was not altered during the experiment, even if conditions were expected to be less favourable for plant growth. The pots with continuously flooded plants were placed in holes in a white plastic sheet which was put over the benches to prevent evaporation from the bench and growth of algae. Shoot length, shoot fresh mass, shoot and root dry mass, and leaf area were measured monthly $(n=6)$.

Table 1. The experimental setup (experiment 3 ) and the resulting growth of Ficus benjamina exotica in relation to fertigation schedule. The fertigation schedule is given as frequency per week * flooding duration in minutes. Flooding height was $0.02 \mathrm{~m}$ in all treatments. Plant growth data are given per plant. LSD = least significant difference.

\begin{tabular}{|c|c|c|c|c|c|c|c|c|}
\hline \multicolumn{2}{|c|}{ Fertigation schedule } & Continuous & $4 * 30$ & $4 * 30$ & $4 * 5$ & $2 * 30$ & $2 * 30$ & LSD \\
\hline \multicolumn{2}{|c|}{ EC of fertigation solution $(\mathrm{mS} / \mathrm{cm})$} & 1.7 & 1.7 & 2.2 & 1.7 & 1.7 & 2.2 & \\
\hline Shoot fresh mass & $\mathrm{g}$ & 88.5 & 86.1 & 86.0 & 80.9 & 63.3 & 60.1 & 11.6 \\
\hline Length & $\mathrm{cm}$ & 68.8 & 68.0 & 65.9 & 65.5 & 57.3 & 59.4 & 2.5 \\
\hline Leaf area & $\mathrm{cm}^{2}$ & 2416 & 2336 & 2361 & 2231 & 1742 & 1627 & 313 \\
\hline Leaf number & & 165 & 153 & 158 & 152 & 124 & 116 & 24 \\
\hline Shoot dry mass & $\mathrm{g}$ & 19.4 & 17.7 & 18.6 & 16.9 & 13.9 & 13.4 & 3.5 \\
\hline Root dry mass & $\mathrm{g}$ & 4.58 & 4.05 & 5.04 & 4.58 & 4.64 & 4.34 & 1.22 \\
\hline Total dry mass & $\mathrm{g}$ & 23.9 & 21.8 & 23.7 & 21.4 & 18.6 & 17.7 & 4.7 \\
\hline Shoot/root ratio & & 4.27 & 4.40 & 3.71 & 3.69 & 3.01 & 3.08 & 0.45 \\
\hline
\end{tabular}




\section{Evapotranspiration}

Evapotranspiration, ET, of continuously flooded plants was determined using four balances (Sauter-Kom) attached to a computer (Hewlett Packard 85). On each balance a tray $(h \times w \times l=0.04 \times 0.5 \times 0.6 \mathrm{~m})$ was placed with a water reservoir $(1.2$ $10^{-3} \mathrm{~m}^{3}$ ) above it to maintain a water level of $0.02 \mathrm{~m}$ in the trays. Nine plants were grown on each tray at a density identical to plants grown on benches $\left(25\right.$ plants $\left.\mathrm{m}^{-2}\right)$. To determine transpiration ( $\mathrm{T}$ ) alone, the potting medium of the plants was covered on two of the four balances. Evaporation (E) was calculated as the difference between T and ET measured simultaneously on the other two balances. For periodically flooded plants, ET was measured by weighing eight plants from each bench after flooding, and before the next flooding. Unless mentioned otherwise, ET rates are expressed per $\mathrm{m}^{2}$ bench surface. To convert these rates to rates expressed per $\mathrm{m}^{2}$ potting medium surface, they must be multiplied by 3.5 .

\section{Water content and matric head}

The amount of water added with irrigation was calculated as the difference between masses before and after flooding. The mass of water retained by the potting medium was estimated after subtraction of the mass of the pot, dry mass of the potting medium and plant mass. The average volumetric water content was calculated using the total volume of the potting medium and density of water. The spatial distribution of water within the potting medium was assessed through measurement of the matric head with a specially developed tensiometer system. The system consisted of 30 ceramic cups with a length of $65 \mathrm{~mm}$ and a diameter of $6 \mathrm{~mm}$ (Soil Moisture Equipment Corp, type 652X01-B1M1), each of them connected by a copper tube and a three-way stop-cock to a pressure transducer (Honeywell 141PC15D). Details are given by Van Den Elsen \& Bakker (1992). The transducers were divided over six waterproof boxes (CITO Benelux B.V, type 02.163609). Each box contained a power source $(10 \mathrm{~V})$ controlled by a trigger input (made by DLO Technical and Physical Engineering Research Service, TFDL-DLO). A HP3852A control and data acquisition unit triggered the pressure transducers and registered their output. The tensiometers were installed horizontally at various depths in the potting medium. An interval of 1 hour was used to quantify matric head profiles in between fertigations, and to compare matric head among treatments at a reference height of $0.06 \mathrm{~m}$. Periodically, the tensiometers were used for detailed measurements of the dynamics in the matric head profile within single pots during fertigation.

\section{Physical characterisation of the potting medium}

Sample rings were placed in cultivation pots which were filled with the potting medium, using an automatic filling machine as is common in horticultural practice. After filling, the pots were placed on a flooded bench system. Subsequently, they were wetted by spraying. Samples were left on the flooded bench system for two flooding periods before the rings were carefully removed and saturated in the labora- 
tory by slowly raising a water table. This procedure guaranteed that the physical characterisation reflected as closely as possible the densities which are obtained under growing conditions on a flooded bench fertigation system.

The main drying curve and the hydraulic conductivity characteristic were determined by the evaporation method $(\mathrm{n}=4)$ (Boels et al., 1978; Tamari et al., 1993; Wind, 1969). Samples were prepared as described above, using rings with a diameter of $0.11 \mathrm{~m}$ and a height of $0.08 \mathrm{~m}$. Separate samples, using rings with a diameter and height of $0.05 \mathrm{~m}$, were used to determine a drying and wetting cycle with a reversal point at $h_{m}=-2 \mathrm{~m}$ (Klute, 1986). The hydraulic conductivity at saturation was measured by the constant head method using rings with a diameter and height of $0.2 \mathrm{~m}$ $(\mathrm{n}=3)$ (Klute \& Dirksen, 1986).

\section{Mathematical representation of physical characteristics}

We used analytical expressions proposed by Van Genuchten (1980; Van Genuchten $\&$ Nielsen, 1985) and by Mualem (1986) to describe the hydraulic characteristics. The Van Genuchten expression of the water retention characteristic is given by:

$$
\left(\theta-\theta_{\mathrm{r}}\right) /\left(\theta_{\mathrm{s}}-\theta_{\mathrm{r}}\right)=\left(1+\left(\alpha\left|\mathrm{h}_{\mathrm{m}}\right|\right)^{n}\right)^{-m},
$$

with $h_{m}$ representing the matric head $(m), \theta_{r}$ and $\theta_{s}$ the residual volumetric water content and the volumetric water content at saturation, respectively, and $\alpha\left(\mathrm{m}^{-1}\right), n$ $(-)$ and $m(-)$ are shape parameters. Following Kool \& Parker (1987) and Dirksen et al. (1993), we use Equation [1] also for hysteretic scanning curves in between the main drying and main wetting curves, but now with a parameter vector $\left(\theta_{\mathrm{s}}^{*}, \theta_{\mathrm{r}}{ }^{*}, \alpha, n\right.$, $m$ ) in which $\alpha=\alpha_{d}$ for a drying curve and $\alpha=\alpha_{w}$ for a wetting curve. The parameters $\theta_{\mathrm{s}}^{*}$ and $\theta_{\mathrm{r}}^{*}$ are given by:

$$
\begin{aligned}
& \theta_{\mathrm{r}}^{*}=\left(-\mathrm{B} \theta_{\mathrm{rev}}+\mathrm{A} \theta_{\text {clos }}\right) /(\mathrm{A}-\mathrm{B}), \\
& \theta_{\mathrm{s}}^{*}=\left((1-\mathrm{B}) \theta_{\mathrm{rev}}+(\mathrm{A}-1) \theta_{\text {clos }}\right) /(\mathrm{A}-\mathrm{B}),
\end{aligned}
$$

where A equals $\left(1+\left(\alpha\left|\mathrm{h}_{\text {rev }}\right|\right)^{n}\right)^{-m}$, and B equals $\left(1+\left(\alpha\left|\mathrm{h}_{\mathrm{clos}}\right|\right)^{n}\right)^{-m}$. The subscripts rev and clos refer to the reversal point, which is the point of departure for a scanning curve, and the closure point, which is assumed to be the reversal point of the previous scanning loop (see Figure 1). Equations [1] through [3] empirically describe the full hysteretic nature of the water retention characteristic with a set of six parameters $\left(\theta_{\mathrm{s}}, \theta_{\mathrm{r}}, \alpha_{\mathrm{d}}, \alpha_{\mathrm{w}}, n, m\right)$.

We use an expression given by Van Genuchten (1980) and Mualem (1986) to relate the hydraulic conductivity to the matric head, $\mathrm{h}_{\mathrm{m}}$ :

$$
K\left(h_{m}\right)=K_{s} \frac{\left[\left(1+\left(\alpha\left|h_{m}\right|\right)^{n}\right)^{m}-\left(\alpha\left|h_{m}\right|\right)^{n-1}\right]^{2}}{\left(1+\left(\alpha\left|h_{m}\right|\right)^{n}\right)^{m(l+2)}}
$$

where $\mathrm{K}_{\mathrm{s}}$ is the hydraulic conductivity at saturation $(\mathrm{m} / \mathrm{s})$, and $l(-)$ is an empirical constant, and $m$ and $n$ are restricted to $m=1-1 / n$. A nonlinear least square fitting procedure (RETC) was used to estimate the parameters $\mathrm{K}_{\mathrm{s}}, l, \alpha_{\mathrm{d}}, n$ (and $m$ ), $\theta_{\mathrm{s}}$ and $\theta_{\mathrm{r}}$ of Equations [1] and [4], fitting to the main drying curve and the hydraulic conduc- 


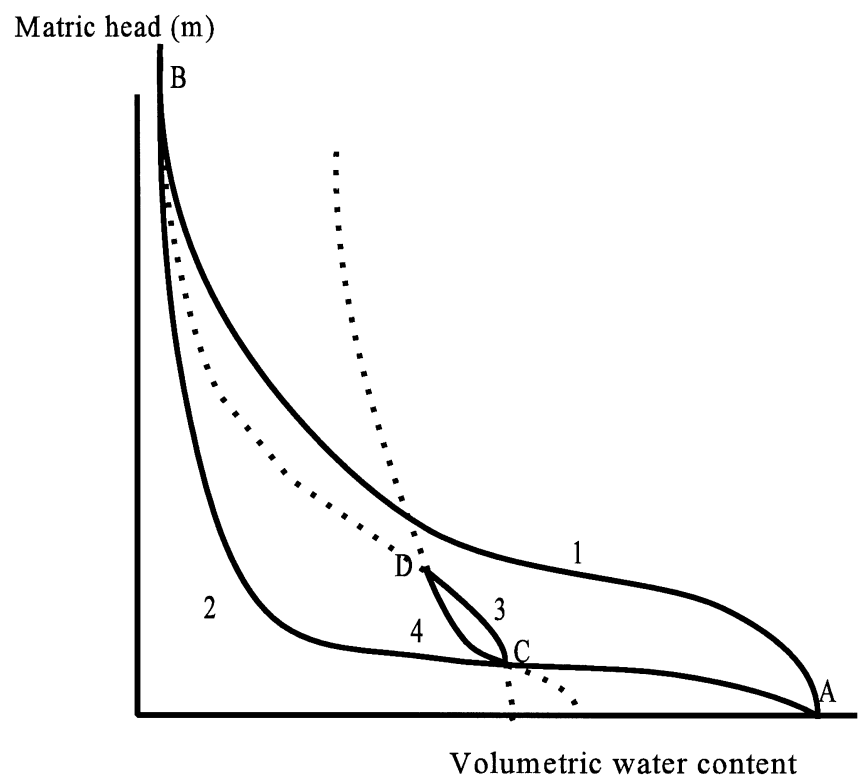

Figure 1. A schematic sequence of cyclical wetting and drying, illustrating the use of Equations [1] through [3] to generate wetting and drying scanning curves of a water retention characteristic. Drying starts from saturation (point A) following curve 1, the main drying curve, which approaches the residual water content in point B. This is followed by wetting according curve 2 , the main wetting curve. Wetting continues till a reversal occurs in point $\mathrm{C}\left(\mathrm{h}_{\mathrm{rev}, \mathrm{C}}, \theta_{\mathrm{rev}, \mathrm{C}}\right)$. From this point a primary drying scanning curve departs (curve 3) which is calculated according to Equations [1] and [3]. This curve is followed till a new reversal occurs in point $\mathrm{D}\left(\mathrm{h}_{\mathrm{rev}, \mathrm{D}}, \theta_{\mathrm{rev}, \mathrm{D}}\right)$. From here a wetting scanning curve departs $($ curve 4$)$. We assume that this curve is closed in the reversal point of the previous scanning loop, point C. Curve 4 is calculated according to Equations [1], [2], and [3], using the known points D and C as reversal and closure points, respectively. If wetting continues beyond point $\mathrm{C}$, the remaining part of the retention characteristic is described by the main wetting curve, curve 2. As a result of hysteresis, in situ relations between $h_{m}$ and $\theta$ are in between curves 1 and 2 .

tivity data simultaneously (Van Genuchten et al., 1991; Leij et al., 1992). In the absence of the main wetting curve, a hysteretic wetting curve was used to estimate the value of $\alpha_{w}$, as suggested by Kool \& Parker (1987).

\section{Results}

\section{Physical characteristics of the potting medium}

Sample preparation without artificial compaction resulted in a bulk density of the potting medium of $100 \mathrm{~kg} / \mathrm{m}^{3}$, and a porosity of 0.9 . A large proportion of the pores was filled with air at high matric heads (Figure 2A), when the medium was drained from saturation. The best fit according to the mathematical description given by Equation [1] showed good agreement at matric heads above $-1 \mathrm{~m}$ and a slight under- 
estimation between -1 and $-2 \mathrm{~m}$ head (Figure 2A). The parameters of Equation [1] leading to the best fit of the main drying curve are given in table 2. Measured data of a wetting curve starting from $\mathrm{h}_{\mathrm{m}}=-2 \mathrm{~m}$ to saturation were used to estimate the parameter $\alpha_{\mathrm{w}}$. The best fit was obtained with $\alpha_{\mathrm{w}}=9.010^{-3} \mathrm{~m}^{-1}$. Using this parameter value and Equations [1] and [2], a predicted wetting curve starting from $-1.2 \mathrm{~m}$ is in close agreement with a wetting curve measured by Bakker \& Kabat (1990) for the same medium (Figure 2A). Comparing wetting curves and drying curves shows that hysteresis significantly reduced the volumetric water content at high matric heads.

The hydraulic conductivity at saturation equalled $1.010^{-3} \mathrm{~m} \mathrm{~s}^{-1}\left( \pm 1.510^{-4}\right)$, and decreased several orders of magnitude to less than $10^{-10} \mathrm{~m} \mathrm{~s}^{-1}$ at volumetric water contents below 0.2 (Figure 2B). The high conductivity resulted in inaccurate estimates of the conductivity near saturation for the medium used in this study. Additional data from Bakker \& Kabat (1990) on the same medium were consistent with our measurements but also failed to obtain the conductivity near saturation (Figure 2B). Since there were no additional data available in the range $\theta=0.6$ to saturation, the conductivity at saturation was fixed at the measured value of $1.010^{-3} \mathrm{~m} / \mathrm{s}$, and the conductivity data at $\theta<0.6$ were fitted simultaneously with the retention data according to Equations [1] and [4] (Figure 2B and Table 2).

A

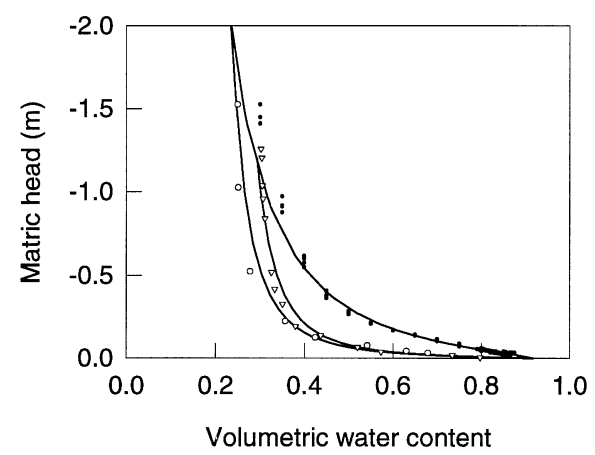

B

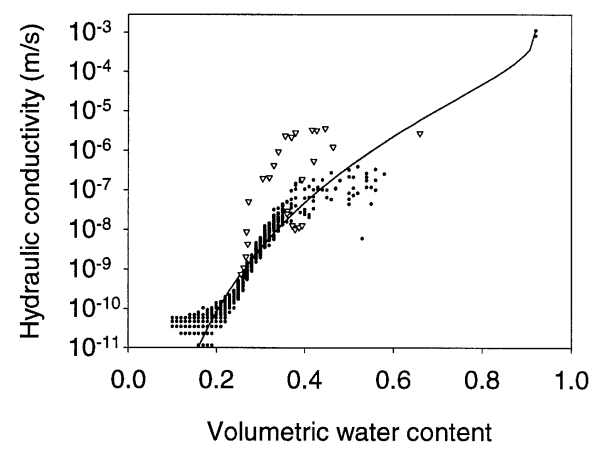

Figure 2. The water retention characteristic (A) for a sample drained from saturation (O), and two samples wetted after drainage from saturation with reversal points at $-2.0 \mathrm{~m}(\bigcirc)$ and $-1.2 \mathrm{~m}(\nabla, \mathrm{Bakker} \&$ Kabat, 1990), respectively, and the hydraulic conductivity (B) for unsaturated samples. Additional data for the same medium measured by Bakker \& Kabat (1990) are presented by a triangle ( $\nabla)$. All lines refer to fitted relations according to the Van Genuchten and Van Genuchten-Mualem equations with the parameters listed in Table 2.

Table 2. Estimated parameters of Equations [1] and [4] obtained by fitting to measured water retention and hydraulic conductivity data for a potting medium consisting of peat $(75 \%)$ and perlite $(25 \%)$.

\begin{tabular}{llllcll}
\hline$\theta_{\mathrm{r}}$ & $\theta_{\mathrm{s}}$ & $n$ & $m$ & $\alpha_{\mathrm{d}}\left(\mathrm{m}^{-1}\right)$ & $\alpha_{\mathrm{w}}\left(\mathrm{m}^{-1}\right)$ & $l$ \\
0.0 & 0.92 & 1.42 & 0.30 & $1.3010^{-3}$ & $9.010^{-3}$ & 2.35 \\
\hline
\end{tabular}




\section{Plant growth}

Plant size and biomass partitioning were affected by fertigation schedule. Shoot mass, shoot-root ratio, shoot length, leaf size and leaf number all decreased with decreasing fertigation frequency (Table 1). A flooding duration of 5 minutes did not affect plant growth compared to a flooding duration of 30 minutes. Root mass was not significantly affected by fertigation schedule. Visually there was no effect of fertigation schedule on root development, except for continuously flooded plants, where roots with a larger diameter grew outside the pot directly into the solution. Most of the roots were in lower regions of the pot and were absent in the uppermost centimetre, probably due to high salinity in these layers (Otten, 1994). The nutrient level (EC) hardly affected plant growth. Only in combination with high fertigation frequency, shoot-root ratio decreased with increasing EC. Plant height, leaf area, and plant mass were not significantly affected by EC under these conditions.

\section{Evapotranspiration of the potted plants}

Evapotranspiration, measured from April to June 1990, varied from $0.75 \mathrm{~kg} \mathrm{~m}^{-2}$ day $^{-1}$ at the start to $3.70 \mathrm{~kg} \mathrm{~m}^{-2}$ day $^{-1}$ at the end, with large variations between successive days (Figure 3). Average ET over the three experiments was $1.7 \mathrm{~kg} \mathrm{~m}^{-2} \mathrm{day}^{-1}$ $\left(0.066 \mathrm{~kg}\right.$ plant $\left.^{-1} \mathrm{day}^{-1}\right)$ with a minimum of 0.4 and a maximum of $4.1 \mathrm{~kg} \mathrm{~m}^{-2} \mathrm{day}^{-1}$. Evapotranspiration was significantly affected by the fertigation schedules, with highest evapotranspiration for continuously flooded plants. The evapotranspiration was lower, but not significantly different, at higher nutrient concentrations of the fertigation solution (Table 3).

A considerable amount of water was lost by evaporation from the potting medium surface (Table 3). The fraction of evapotranspiration lost as a result of evaporation reduced over time from 0.9 to 0.15 , following an exponential decline with increasing

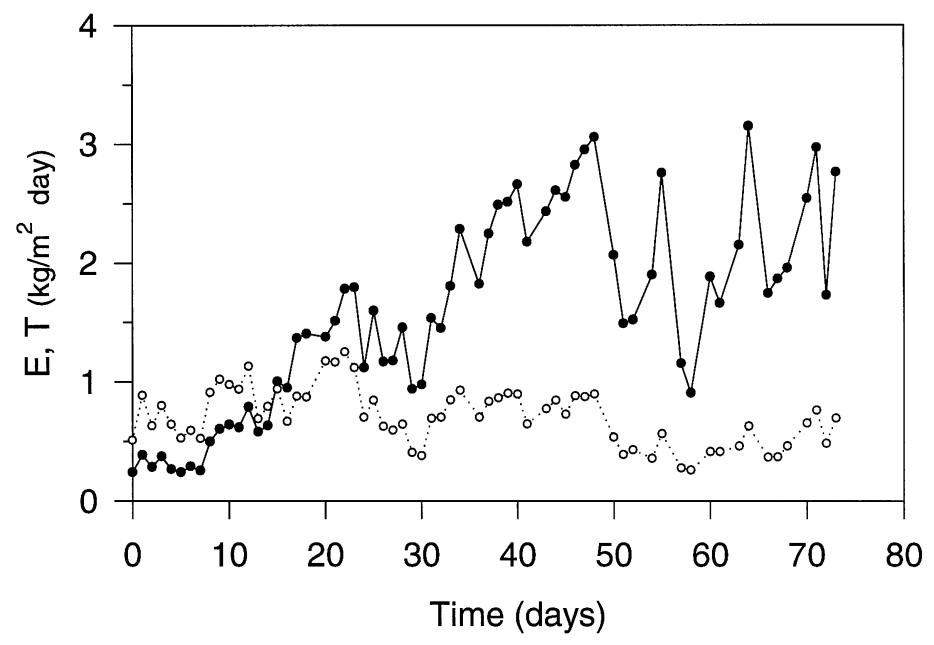

Figure 3. Dynamics in daily transpiration $(\boldsymbol{O}$, continuous line) and in daily evaporation $(\bigcirc$, dashed line) for continuously flooded Ficus benjamina exotica plants on a flooded bench fertigation system. 
Table 3. Cumulative evapotranspiration (ET), transpiration (T) and evaporation (E) $\left(\mathrm{kg} \mathrm{plant}^{-1}\right)$ in relation to fertigation schedule. Values indicated by an asterisk are believed to be less accurate. LSD $=$ least significant difference.

\begin{tabular}{llllll}
\hline Schedule & EC & ET & T & E & E/ET *100 \\
Continuous & 1.7 & 5.67 & 4.68 & 0.99 & 17.5 \\
$4 * 30 \mathrm{~min}$ & 1.7 & 4.94 & 3.79 & 0.97 & 19.6 \\
$4 * 30 \mathrm{~min}$ & 2.2 & 4.51 & 3.38 & 1.13 & 25.1 \\
$4 * 5 \mathrm{~min}$ & 1.7 & 4.20 & $3.65^{*}$ & $0.54^{*}$ & $12.8^{*}$ \\
$2 * 30 \mathrm{~min}$ & 1.7 & 3.84 & $3.41^{*}$ & $0.44^{*}$ & $11.5^{*}$ \\
$2 * 30 \mathrm{~min}$ & 2.2 & 3.74 & $2.96^{*}$ & $0.78^{*}$ & $20.8^{*}$ \\
LSD & & 0.37 & 0.34 & 0.39 & 7.3 \\
\hline
\end{tabular}

leaf area of the plants. The cumulative amount of water lost during the entire cultivation period by evaporation for continuously flooded plants varied among the three experiments from $19 \%$ to $41 \%$ of the total loss. The highest percentage $(41 \%)$ was found during the winter experiment when plants remained small for several weeks. The fraction lost through evaporation was hardly affected by the fertigation schedules (Table 3). The evaporation for the drier treatments, indicated with an asterisk in Table 3, is an underestimation as, in the final stages of the cultivation, the potting medium became very dry in these treatments. Since the pots used to estimate transpiration were covered with plastic, less water was lost by evaporation and concomitantly more water was available for transpiration. Therefore, covering the potting medium increased transpiration under dry conditions compared to the standard treatment, resulting in an underestimation of the evaporation, as this was calculated as the difference between evapotranspiration of the standard pots and transpiration of the covered ones. Higher nutrient levels in the fertigation solution only reduced the transpiration as a result of higher EC in the root environment (Table 3).

\section{Dynamics of water in the potting medium}

Highest volumetric water content was found for continuously flooded plants, where average volumetric water content in 60 days gradually increased from 0.63 to 0.71 (Figure 4). For plants that were flooded four times a week for 30 minutes, volumetric water content reached after fertigation gradually decreased in three months from 0.54 to 0.45 . A flooding duration of five minutes was sufficient in the beginning when evapotranspirative demand was relatively small, but the volumetric water content after flooding dropped sharply with increasing time (Figure 4). If plants were flooded twice a week for 30 minutes, water content after flooding also decreased sharply when evapotranspiration increased. A flooding period of 30 minutes was not long enough to compensate for the low frequency.

The hourly measured matric head reflected the drying and wetting cycles induced by fertigation with lowest values just before and highest values just after flooding. The lowest matric head for plants that were flooded four times a week for 30 minutes measured at a height in the pot of $0.06 \mathrm{~m}$ was $-1.53 \mathrm{~m}(\mathrm{SE}=0.60, \mathrm{n}=9)$. For plants 


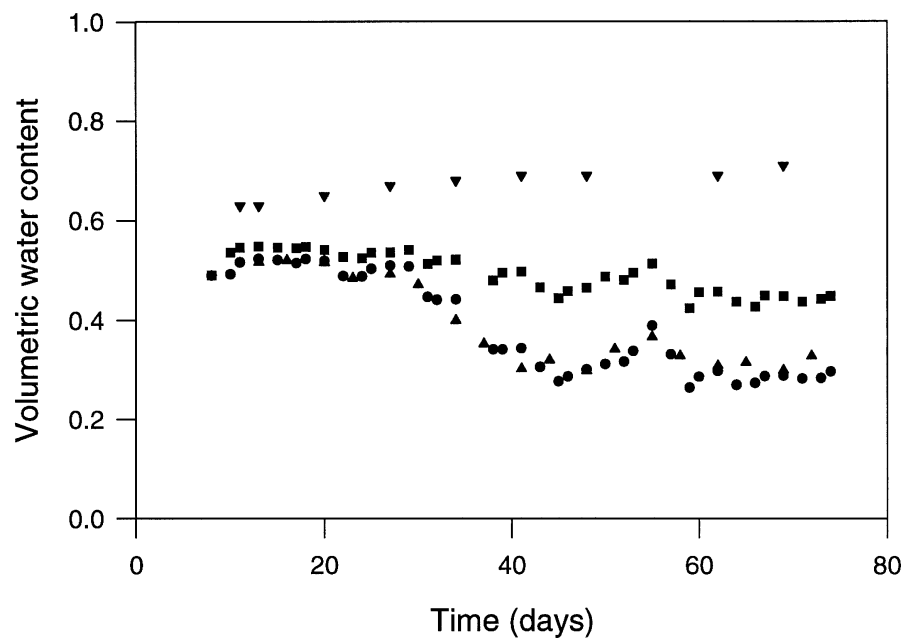

Figure 4. Dynamics in water content of the potting medium. The average volumetric water content measured after flooding for plants that were flooded continuously ( $\boldsymbol{\nabla}), 4$ times a week for 30 minutes (ם), 4 times a week for 5 minutes (O), and twice a week for 30 minutes (A) versus time since start of the cultivation period (experiment 3 ).

that were flooded four times a week for five minutes the lowest matric head was $-7.18 \mathrm{~m}(\mathrm{SE}=1.73, \mathrm{n}=9)$, and for plants flooded twice a week for 30 minutes it dropped below $-8.0 \mathrm{~m}$, which is the lowest value that can be measured with these tensiometers. Continuously flooded plants remained at near hydrostatic equilibrium throughout the growing period.

Once flooding was stopped, the matric head initially decreased equally at all depths in the potting medium (Figure 5), maintaining conditions close to hydrostatic equilibrium. However, as evapotranspiration proceeded the matric head eventually decreased more rapidly in lower layers than in higher layers of the potting medium. It can therefore be concluded that under drier conditions redistribution of water

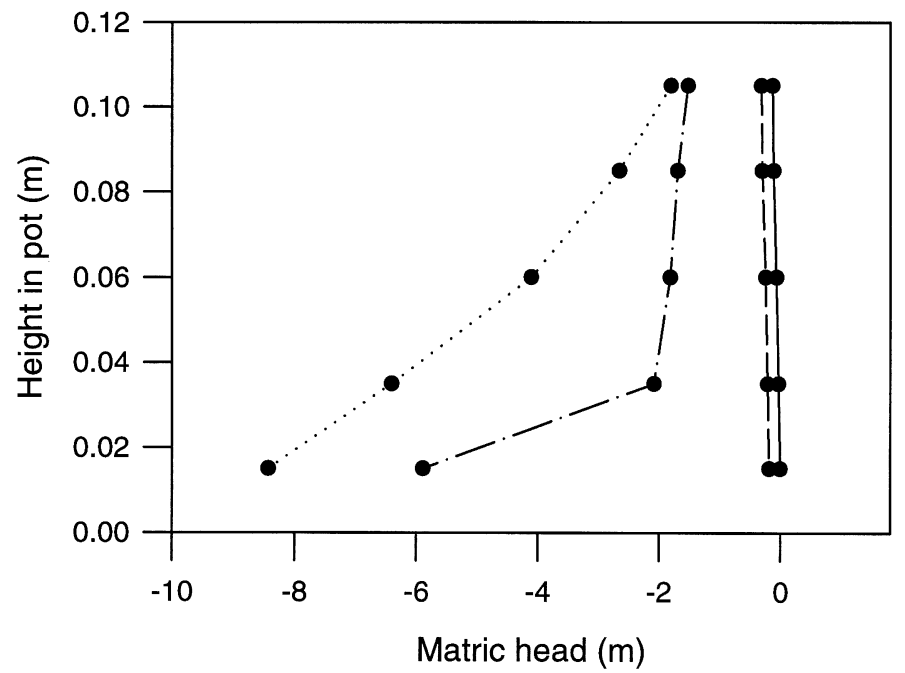

Figure 5. Vertical profiles in matric head as they developed after 0 (continuous line), 20 (dashed line), 40 (dash-dot line), and 60 (dotted line) hours of transpiration following subirrigation of a Ficus benjamina plant. 
within the medium could not keep up with evapotranspiration and localised extraction from the lower layers. The uptake from lower layers is consistent with the observation that the majority of roots was found there and that the salinity increased with height.

Tensiometers were also used to assess the degree of saturation during flooding. When the pots were flooded, the matric head immediately increased to zero in the layer of the potting medium that was flooded, indicating a quick saturation. The matric head of higher layers in the potting medium, however, increased more slowly with time. Higher layers were wetted by vertical transport of water within the potting medium. When flooding started after the potting medium had dried to a matric head of $-1.10 \mathrm{~m}$, it took over 40 minutes of flooding to reach a hydrostatic equilibrium. In practice, however, flooding periods of 5 minutes are more common. With short flooding durations, only frequent flooding can prevent drying out of the potting medium.

We define the volumetric absorption of water as the supply during flooding resulting from capillary rise $\left(\mathrm{m}^{3}\right)$ divided by pot volume $\left(\mathrm{m}^{3}\right)$. For the wide range of conditions that occurred during the experiments, the volumetric absorption was strongly related to the average volumetric water content of the potting medium before flooding (Figure 6). At high water contents (above 0.45) there was no difference between 5 or 30 minutes of flooding. However, with decreasing average volumetric water content the differences between flooding periods of 5 and 30 minutes increased, although even at low volumetric water contents most capillary rise took place within 5 minutes (Figure 6). As will be discussed below, this relationship between volumetric

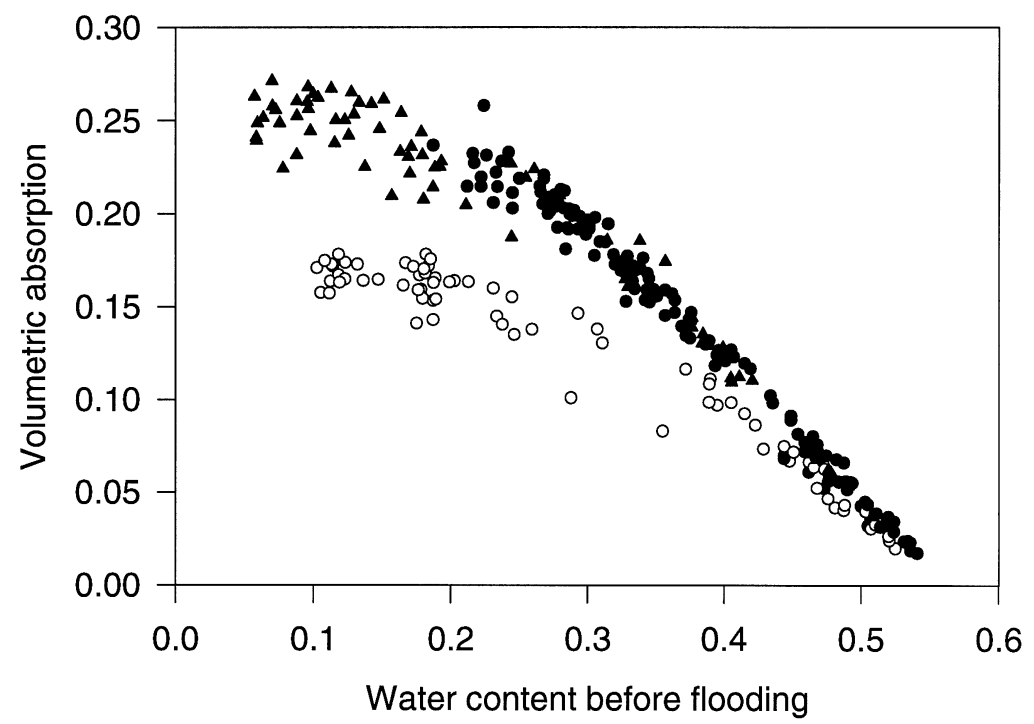

Figure 6. The volumetric absorption of water by the potting medium (supply during flooding resulting from capillary rise $\left(\mathrm{m}^{3}\right)$ divided by pot volume $\left(\mathrm{m}^{3}\right)$ ) in relation to volumetric water content before flooding. The plants were flooded twice a week for 30 minutes $(\boldsymbol{\Delta})$, four times a week for 30 minutes (๑), or four times a week for 5 minutes $(\bigcirc)$. 
absorption and volumetric water content is a useful tool to estimate fertigation requirements with respect to evapotranspiration.

\section{Discussion}

We have presented a coherent data set comprising physical characterisation, evapotranspiration and dynamics of water in the root environment for potted plants grown on a flooded bench fertigation system. A comprehensive study like this one is an essential step towards understanding the temporal and spatial dynamics of water in the root environment, and towards analysis of the buffer capacity of the potting medium in relation to variation in evapotranspiration. In addition, the results allow for validation of a model linking the evapotranspirative demand with the physical characteristics of the potting medium and the fertigation schedule imposed, which will enable broader analysis of the system and conclusions beyond those for the potting medium used in this study.

A sufficiently large air content at high matric heads is often considered as an important characteristic of a horticultural medium. Cassel \& Nielsen (1986) demonstrated that air content is also dictated by container geometry and introduced the concept of container capacity to analyse container geometry and water retention characteristic as one entity. They defined container capacity as the amount of water held by a medium after drainage from saturation, which can be estimated from geometry of the container and the main drying curve. For the medium and container used in this study, the container capacity equals $0.8210^{-3} \mathrm{~m}^{3}$. Our results show, however, that even for continuously flooded plants the container capacity was not reached (see Figure 4). The estimate is based on the drying curve of the water retention characteristic which reflects the conditions at the start of the growing period. Physical characteristics of horticultural media change over time due to root growth, rearrangement of particles after repeated wetting and drying or decomposition of organic matter (Nelson and Fonteno, 1991; Klougart, 1983; Otten, 1994). On the flooded bench system, the physical characteristics of this potting medium were affected by both root growth and fertigation schedule (Otten, 1994), with an increase in water retention at matric heads below $-0.3 \mathrm{~m}$. We conclude therefore that the change in the physical conditions cannot be the main reason for the reduction in the water holding capacity after flooding. We conjecture that this reduction is the result of hysterisis in the water retention characteristic. Since the medium on the flooded bench system is wetted by capillary rise, the water retention characteristic is more appropriately described by a wetting curve than by the main drying curve. Comparing wetting curves to drying curves, hysteresis reduces the volumetric water content at a given matric head. Although the role of hysteresis in other growing systems needs further investigation, it is clear that hysteresis in the water retention characteristic should not be overlooked when the medium is used on a flooded bench fertigation system, and that it significantly reduces the amount of water available for the plant. As a result of hysteresis in the water retention characteristic, dry conditions of the potting medium, even if they would occur incidentally, should be avoided on a 
flooded bench fertigation system.

The hydraulic conductivity at saturation was relatively high compared to that of natural soils, but was within a range of $5.810^{-9}-5.810^{-3} \mathrm{~m} / \mathrm{s}$, reported for several horticultural media (Otten, 1994). Hydraulic conductivities for unsaturated media are rarely reported. Importantly, the hydraulic conductivity decreased by several orders of magnitude with decreasing volumetric water content. This is particularly relevant, since significant changes in water content, and consequently in hydraulic conductivity, will occur within narrow ranges of matric head for most horticultural media.

The concept of container capacity, following either a main drying curve or a scanning wetting curve, does not account for dynamics in the system and deviation from a hydrostatic equilibrium. Redistribution of water in this potting medium could no longer keep up with water uptake by plant roots when the matric head dropped below $-1.5 \mathrm{~m}$. Under conditions occurring on the flooded bench system, this matric head corresponded with a volumetric water content of 0.22 . A volumetric water content of 0.22 can therefore be considered as a lower threshold value for practically realistic fertigation schedules. The volumetric absorption by the potting medium during fertigation which would occur at this threshold volumetric water content of 0.22 equals 0.15 for 5 minutes flooding and 0.22 for 30 minutes of flooding (see Figure 6). We propose that these values represent an actual buffer capacity of the potting medium in this particular growing system. It is evident that this value is much lower than the container capacity, which equalled 0.82 , and should be regarded as a potential buffer capacity. The actual buffer capacity of the potting medium used on a flooded bench fertigation system depends on container geometry, flooding duration, and physical characteristics of the potting medium, particularly the hysteresis in the water retention characteristic and the hydraulic conductivity characteristic.

The actual buffer capacity together with knowledge on evapotranspiration can now be used to identify minimum fertigation requirements for this potting medium. Evapotranspiration in between successive fertigations should not exceed the actual buffer capacity to prevent the medium to become dry in the long term. For the container used in this study with a volume of 1 litre, and a plant density of 25 plants $/ \mathrm{m}^{2}$, the evapotranspiration between two fertigations, therefore, should not exceed 3.75 $\mathrm{kg} / \mathrm{m}^{2}(=0.15 * 25)$ and $5.5 \mathrm{~kg} / \mathrm{m}^{2}(=0.22 * 25)$ for 5 and 30 minutes of flooding, respectively. Evapotranspiration varied significantly among days throughout the growing season. The mean evapotranspiration rate of $1.7 \mathrm{~kg} \mathrm{~m}^{2}$ day $^{-1}$ would require a fertigation frequency of once every two days if flooded 5 minutes and twice a week if flooded 30 minutes. Evapotranspiration, however, varied amongst days with a highest measured evapotranspiration rate of $4.1 \mathrm{~kg} \mathrm{~m}^{-2} \mathrm{day}^{-1}$. The fertigation can best be based on the highest evapotranspiration rate, since dry conditions should be avoided in a flooded bench system due to hysteresis in the water retention characteristic. For such rates a daily fertigation would be required. The sudden drop in water content for periodically flooded plants (see Figure 4) can now be easily understood from the increase in evapotranspiration (see Figure 3). The most effective strategy at this stage will be to increase the frequency rather than prolonging the flooding duration since the majority of the water is absorbed in the first minutes making two short fertigations more effective than one longer period. The relationship between volumetric 
absorption and water content before flooding (Figure 6) is a helpful tool to estimate minimum requirements for fertigation. It is a simplified graphical interpretation of the system combining the physical characteristics of the medium, the geometry of the container, the evapotranspiration and the fertigation schedule and system. Note that the relationship can be determined empirically as described in this paper, or can be constructed mathematically using a simulation model and the hydraulic characteristics and boundary conditions of the system (Otten, 1994).

The results in this study allow for important conclusions on processes dictating the dynamics of water in the root environment of potted plants in a widely used fertigation system. We quantified the evapotranspirative demand of Ficus benjamina plants, determined the short and long term variation in evapotranspiration, and showed that a large part of the water is lost through evaporation. This is particularly important for the distribution of nutrients within the potting medium, as it is likely to cause accumulation in the top layer. We have shown that the buffer capacity of the potting medium not only depends on the physical characteristics but also on the container geometry and fertigation schedule and technique. Physical characteristics of a potting medium therefore should not be seen independently from the fertigation system. Hysteresis in the water retention characteristic and the hydraulic conductivity in unsaturated media both are crucial for the dynamics in the root environment. Yet we note that these characteristics are not routinely quantified for horticultural media. For the particular potting medium used in this study to grow Ficus benjamina plants on a flooded bench fertigation system a daily fertigation of 5 minutes would be required under high evapotranpirative demand, whereas a weekly fertigation would be sufficient during the early stage of cultivation. A more precise specification of the fertigation schedule would require an analysis of the dynamic behaviour of water in the root environment as can be achieved by simulation.

\section{Acknowledgements}

Thanks are due to the Research Station for Floriculture and Greenhouse Vegetables at Aalsmeer, The Netherlands for the use of their facilities and in particular to Mr. J. van Zoest, Mr. T. van der Wurff, Mrs. M. Warmenhoven, and Mr. N. Straver for support in the experimental work. We also wish to thank Mr. J. Elbers of the Winand Staring Centre at Wageningen, The Netherlands, who constructed the tensiometers used in this study.

\section{References}

Bakker, J.A. \& P. Kabat, 1990. Soil physical characterisation of potting media for flooded bench fertigation systems (In Dutch). Report 71, Winand Staring Centre (SC-DLO), Wageningen, 45 pp.

Boels, D., J.B.M.H. Van Gils, G.J. Veerman \& K.E. Wit, 1978. Theory and systems of automatic determination of soil moisture characteristics and unsaturated hydraulic conductivities. Soil Science 126: 191-199.

Cassel, D.K. \& D.R. Nielsen, 1986. Field Capacity and Available Water Capacity. In: A. Klute (Ed.). 
Methods of soil analysis, part 1: Physical and mineralogical methods. 2nd ed. Agronomy Series No. 9. American Society of Agronomy, Inc., Madison, pp. 901-926.

De Krey, C. \& N. Straver, 1988. Flooded-bench irrigation: effect of irrigation frequency and type of potting soil on growth of Codiaeum and on nutrient accumulation in the soil. Acta Horticulturae 221: $245-252$.

Dirksen, C., J.B. Kool, P. Koorevaar \& M.Th. Van Genuchten, 1993. HYSWASOR - Simulation model of hysteretic water and solute transport in the root zone. In: D. Russo \& G. Dagan (eds.), Water flow and solute transport in soils: developments and applications in memoriam Eshel Bresler (1930-1991). Springer, Berlin, pp. 99-122.

Heinen, M., 1997. Dynamics of water and nutrients in closed, recirculating cropping systems in glasshouse horticulture with special attention to lettuce grown in irrigated sand beds. PhD Thesis. Wageningen Agricultural University, Wageningen, $270 \mathrm{pp}$.

Klougart, A., 1983. Substrates and nutrient flow. Acta Horticulturae 150: 297-313.

Klute, A., 1986. Water retention: Laboratory methods. In: A. Klute (Ed.). Methods of soil analysis, part 1: Physical and mineralogical methods. 2nd ed. Agronomy Series No. 9. American Society of Agronomy, Inc., Madison, pp. 635-662.

Klute, A. \& C. Dirksen, 1986. Hydraulic conductivity and diffusivity: Laboratory methods. In: A. Klute (Ed.). Methods of soil analysis, part 1: Physical and mineralogical methods. 2nd ed. Agronomy Series No. 9. American Society of Agronomy, Inc., Madison, pp. 687-734.

Kool, J.B. \& J.C. Parker, 1987. Development and evaluation of closed-form expressions for hysteretic soil hydraulic properties. Water Resources Research 23: 105-114.

Leij, F.J., M.Th. Van Genuchten, S.R. Yates, W.B. Russel \& F. Kaveh, 1992. RETC: A computer program for analyzing soil water retention and hydraulic conductivity data. In: M.Th. Van Genuchten, F.J. Leij \& L.J. Lund (Eds.). Indirect methods for estimating the hydraulic properties of unsaturated soils. University of California, Riverside, pp. 263-272.

Mualem, Y. 1986. Hydraulic conductivity of unsaturated soils: Prediction and formulas. In: A. Klute (Ed.). Methods of soil analysis, part 1: Physical and mineralogical methods. 2nd ed. Agronomy Series No. 9. American Society of Agronomy, Inc., Madison, pp. 799-823.

Nelson, P.V. \& W. Fonteno, 1991. Physical analysis of rockwool slabs and effects of fiber orientation, irrigation frequency and propagation technique on Chrysantheum production. Journal of Plant Nutrition 14: 853-866.

Otten, W., 1994. Dynamics of water and nutrients for potted plants induced by flooded bench fertigation: experiments and simulation. PhD Thesis. Wageningen Agricultural University, Wageningen, 115 pp.

Ploeger, C. 1992. The organization of the pot plant cultivation in The Netherlands (In Dutch). Publication 4. 130. Agricultural Economics Institute (LEI-DLO), The Hague, 96 pp.

Tamari, S., L. Bruckler, J.M. Halbertsma \& J. Chadoeuf, 1993. A simple method for determining soil hydraulic properties in the laboratory. Soil Science Society of America Journal 57: 642-651.

Van den Elsen, H.G.M. \& J.W. Bakker, 1992. A universal device to measure the pressure head for laboratory use or long term stand-alone field use. Soil Science 54: 458-464.

Van Genuchten, M.Th., 1980. A closed-form equation for predicting the hydraulic properties of unsaturated soils. Soil Science Society of America Journal 44: 892-898.

Van Genuchten, M.Th. \& D.R. Nielsen, 1985. On describing and predicting the hydraulic properties of unsaturated soils. Anneals Geophysics (Gauthier-Villars) 3: 615-628.

Van Genuchten, M.Th., F.J. Leij \& S.R. Yates, 1991. The RETC code for quantifying the hydraulic functions of unsaturated soils. EPA/600/2-91/065. R. S. Kerr Environmental Research Laboratory, U. S. Environmental Protection Agency, Ada, 93 pp.

Van Os, E.A., M.N.A. Ruijs \& P.A. Van Weel, 1991. Closed business systems for less pollution from greenhouses. Acta Horticulturae 294: 49-57.

Wind, G.P., 1969. Capillary conductivity data estimated by a simple method. In: P.E. Rijtema \& H. Wassink (Ed.) Water in the unsaturated zone. Proceedings Wageningen symposium, volume 1. International Association of Scientific Hydrology, Gentbrugge, pp. 181-191. 
